\title{
Acerca de la Poesía Alemana en el Perú: nuevas apuntaciones
}

\author{
por Estuardo NúÑEz
}

A los tres años de la aparición de mi libro sobre Autores Germanos en el Perú, y.gracias al hallazgo o ubicación de nuevos datos o elementos documentales, puedo ofrecer algunas facetas nuevas de la acogida que tuvieron en el Perú esos y otros grandes valores de la cultura europea que han nutrido la inquietud de las generaciones literarias peruanas en los últimos ciento cincuenta años. El campo de estas indagaciones sobre la literatura comparada en que estoy empeñado desde hace algún tiempo, resulta cada vez más amplio y rico, y de una riqueza para muchos y para mi mismo completamente insospechada. Tal cúmulo de elementos de lo que podría llamarse con lenguaje científico de nuestros días, la transculturación en el campo literario, esto es, el paso de elementos culturales de una región a otra y el análisis de su recepción o acogida, que deben ser sujetos a examen minucioso y atento, ha de ofrecer sin duda interesantes perspectivas para el definitivo estudio de las llamadas "influencias" literarias en nuestro medio. Pongamos celo en que estas investigaciones en materia de literatura comparada se intensifiquen en otros países de nuestra América que han recibido similares influjos. Persisto en mis trabajos dentro del área del Perú, que ya están adquiriendo un volumen no previsto. Acabo de terminar el segundo tomo de mis trabajos sobre esta materia que se titula Autores Ingleses y norteamericanos en el Perú, y estoy cerca del fin de otros dos volúmenes sobre Autores tranceses y Autores italianos. El material acumulado es ingente en cuanto a datos, fechas de recepción, autores dedicados a las tareas de traducción, examen comparativo de calcos e imitaciones y análisis de versiones publicadas, las más de las veces, en periódicos efímeros y de difícíil consulta. No dejan de 
interesar algunos plagios que también surgen en medio de multitud de obras estimables. Se pone de manifiesto igualmente la tarea altamente encomiable de conocidos y también de ignorados nombres de nuestras letras que se dedicaron en otras épocas al modesto, sacrificado, humilde, y ejemplar oficio de traductores, en donde su obra benedictina y humanista encontró tal vez otrora escasa o ninguna acogida.

\section{Goethe y su resonancia peruana.}

Me ha sido dado encontrar recientemente el primer texto de Goethe inserto en una publicación peruana. Se trata de la versión anónima, en prosa, de un poema juvenil de Goethe, que aparece publicada en "El Instructor Peruano", en 1847 (1), apenas quince años después de la muerte del poeta. Aquella publicación no tuvo seguramente trascendencia alguna por lo aislada e insignificante. Sólo veinticinco años más tarde va a generalizarse el interés y la asimilación en el Perú de esta gran figura de la literatura alemana debido sin duda a circunstancias históricas que deben puntualizarse.

El interés por Goethe y la poesía romántica alemana se hizo general a partir de una fecha histórica : 1872, con la afirmación del poderío alemán a raíz de la guerra franco-prusiana y el logro de la unidad nacional alemana. Tales circunstancias políticas representadas por figuras esplendentes como Moltke y Bismarck, reflejan necesariamente sobre el campo cultural y en forma de expansión del conocimiento de la cultura alemana en el exterior. He tratado ya del caso de Goethe difundido por la acción perseverante denEugenio Larrabure y Unánue que lo retradujo del francés y lo comentó ampliamente en todas sus facetas. No voy a insistir en el empeño magistral de sus traductores directos peruanos como González Prada, Juan de Arona y Federico More, a quienes he dedicado algunas páginas. Quiero ahora revelar a otro eximio traductor del gran poeta alemán : el vate tacneño, por este y otros títulos tan digno, Modesto Molina. En "El Correo del Perú" que desde su aparición hace tanto por difundir la obra de los románticos alemanes y que como se dijo en sus mismas páginas es "el primer periódico de América del Sur que da en castellano las principales poesías diversas de Goethe, que aún son casi desconocidas en la misma Es-

( I) J. W. Goethe, "La Muerte", traducción anónima publicada en "El. Instructor Peruano", tomo Io NP IC, Lima, 1847. Esta publicación reveló por primera vez a diversos poetas alemanes como Heinc, Mauricio IIartmann, Lenau, Grün, Luisa Brachmann, etc. 
paña", se publican también, en setiembre de 1874, (2) tres versiones de lieder de Goethe debidas a la pluma de Molina, entonces residente en Iquique. Mucho contribuyeron estas versiones a confirmar el cabal conocimiento de la lírica alemana, un tanto desvaída en las traducciones escuetas y frías de Larrabure, y a revelar las altas condiciones del poeta alemán que años más tarde harán exclamar a Prada en uno de sus Grafitos :

\section{(A Goethe)}

Entre la densa lobreguez del norte Surges bañado en esplendor heleno, $\mathrm{Y}$ como un hijo a su glorioso padre, La mano tiendes al patriarca Homero. (3)

Por los poemas que publicamos en el Florilegio se podrá juzgar del esfuerzo desplegajo por Molina en su propósito de reflejar la inspira. ción goethiana. No hemos de exagerar el elogio, sin embargo, pues el traslado no muestra el rigor o el encanto de las excelentes versiones de González Prada, uno de los más cabales poetas traductores en las leiras peruanas.

Modesto Molina tradujo al castellano poemas de otros autores alemanes, ingleses e italianos. Hasta donde llegan mis datos existen de él versiones de Heine y Koerner, Byron Y Shakespeare y del itálico Stechetti. He logrado ubicar poemas de los cuatro últimos, mas no todavía los de Heine. En el Florilegio se agrega una bella versión del canto "Mi Patria", de Koerner debida a la pluma preclara de Molina. Las versiones suyas de Byron y Shakespeare acaban de aparecer en mi volumen Autores ingleses y norteamericanos en el Perú.

\section{Heine y su resonancia peruana.}

De los románticos alemanes quien tocó la fibra más sensible de los románticos y modernos peruanos fue sin duda Enrique Heine. Su familiaridad en el mundo latino e hispánico es tanta, que a veces nos

(2) Poemas Adiós, Lejos de ella y Hänsel, en versiones de Modesto Molina, publicados en "El Correo del Perú", Lima, I3 de seticmbre de $187+$, año IV; fechados en Iquique, agosto de 1874 .

(3) M. G. Prada Grafitos, París, Tip. L. Bellenand et Fils, 1937. 
parece impropia su procedencia alemana. En verdad, fue un poeta que se hizo fuera de su patria,en el destierro voluniario, cada vez más afirmado en su residencia francesa y como alguien lo definió, era el ruiseñor nórdico anidado en la peluca de Voltaire.

En mi libro primeramente citado afirmé que las primeras versiones peruanas de Heine se publicaron por 1867, y fueron producto de la pluma de Ricardo Palma. Puedo adicionar ahora otro dato de interés complementario, ya que 20 años antes, en 1849, cuando aún vivía Heine, se publicó en "El Instructor Peruano" (4) con un breve comentario final, la traducción anónima de los 8 primeros cantos de su gran poema Atta Troll, que se subtitulaba "Sueño de una noche de estío". No es posible afirmar ni negar que se trate de una versión peruana o tal vez española. Era muy reciente todavía la publicación de ese memorable poema terminado en 1842, para pensar, sin embargo, que pudiera tratarse de una versión venida a través de España. Probablemente se trataba de una retraducción del francés. Pero lo evidente sigue siendo que frente a esta versión anónima corresponde a Palma la primacía entre los traductores revelados.

La extraordinaria influencia de Heine fue tanta que aún se prolonga hasta nuestros días, lo que no ha conseguido tal vez poeta alguno español o francés del siglo XIX. Favorecieron probablemente ese influjo la calidad de los traductores que Heine encontró en el Perú : Ricardo Palma, Manuel González Prada, José Mendiguren y Samuel Velarde entre los ya estudiados por mí. Los dos primeros fueron abundamente conocidos antes de ahora, mas no los dos últimos, cuyas versiones apenas hace un añ hemos exhumado, Shaciendo justicia a sus autores. Una faceta de la personalidad múltiple de Federico More, también traductor de Heine, $\mathrm{y}$ de tantos líricos alemanes, ha sido igualmente objeto de nuestro comentario elogioso. José Mendiguren pasó ignorado hasta hace poco como hombre de sensibilidad y exquisita cultura. Fue periodista de calidad, escritor inspirado de efímeros artículos que yacen dispersos en revistas y periódicos de fines del siglo diecinueve. Como poeta festivo y autor teatral, encontramos también algunas expre. siones suyas recogidas por IManuel Moncloa y Covarrubias (5). Pero sigo creyendo que su obra más delicada y perdurable serán sus mag. níficas e inspiradas versiones de Heine.

(4) II. Heine, Atta Troll, traducción anónima de los 8 primeros Cantos, con un breve comentario final, en "El Instructor Peruano", Lima, II de sctiembre de 1849 , No 69. El poema completo consta de 27 cantos.

(5) M. Monclada y C. "Los bohemios de 1886 " en Costumbristas y satiricos, Tomo 9, II, Biblioteca de Cultura Peruana dirigida por V. Garcia Calderún. 
Insignes traductores peruanos del alemán.

Puedo adicionar tambiér ahora la noticia de otros traductores peruanos de Heine, y muy estimables por cierto. Con posterioridad a la publicación de mi tantas veces citado libro, he podido identificar al autor de la versión del poema "El Mar" (p.152-153) y completar su texto. Es el autor Arsenio Esquerra apelativo un tanto extraño que más parece un seudónimo. Pero aún no ubico los textos de Heine traducidos por el gran poeta tacneño Modesto Molina.

En cambio, me place agregar los nombres de algunas figuras inte. resantes a la relación de los traductores peruanos de Heine : el de la poetisa arequipeña "Adriana" - Adriana Buendía- constante colaboradora de "El Correo del Perú", y de "La Alborada", y el de Arturo Morales Toledo, redactor de la revista primeramente nombrada.

Deduciendo del texto de los epigrafes trancritos en la lengua origiginal del autor, "Adriana" habría traducido dos lieder ("Mi corazón", "Sli imagen") directamente del alemán. No pienso lo mismo de las versiones de Arturo Morales Toledo, que son más numerosas, y que comprenden varios lieder y una balada: "Los dos granaderos", tal vez uno de los más logrados traslados de Heine en lengua castellana.

La obra de Juan de Arona como traductor del alemán merece un párrafo aparte. A los múltiples seudónimos que Pedro Paz Soldán usó (Juan de Arona, Juan sin tierra, John Lackland, Giovanni senza terra, Aral), debemos agregar el de Un-berufen ("el intruso o incompetente") que utilizó como traductor de Goethe y otros poetas alemanes. Sus predilecciones sobre poesía alemana se demuestran no "sólo en sus versiones tan estimables, sino además en los epígrafes que puso a algunas de sus poesías y aún en el tema mismo de sus poemas.

Una de sus Rimas del Rimac (6) empieza con el siguiente epígrafe:

Da steht ich nun, ich armer Thor!

Uno bin so klug als wie zuvor.

Faust, Goethe

y traduce libremente :

Heme aquí, pobre loco

que ayer no supe nada y hoy tampoco.

y empieza su rima "Mis y $\mathrm{mi}^{\prime \prime}$ :

(6) v. "El Chispazo", No 47, Lima, setiembre 3 de 1892. 
Llevo ya tanto en la vida, que sé lo que es padre y madre, lo que es hermana y querida, lo que es ser yo mismo padre

Estas rimas se publicaron en "El Chispazo". Allí mismo andan unos versos satíricos titulados (7) "Chispazo a la alemancita" :

\author{
Oh Braut von Messina \\ de bucles de oro! \\ pues que tú eres vecina \\ de la que adoro, \\ díle a Fernanda \\ que va acabar conmigo \\ si no se ablanda.
}

Estas estrofas demuestran la familiaridad de Arona con las obras de Goethe y Schiller, a lo que se puede agregar su conocimiento de otros románticos menores como Freiligrath.

Tampoco debemos postergar la mención - al lado de Arona y Prada- de otro valorighorado de nuestras letras muy versado en literatura griega, latina, alemana, italiana, inglesa y francesa: Federico Flores Galindo, asidúo colaborador de li El Correosdel Perún en el decenio del 70 , y que suscribió la mayor parte de su obra con los seudónimos : "Dalmiro" y "E. de Ricof". De sus versiones inglesas ya nos hemos ocupado; ahora nos toca revelar una esforzada versión de Schiller - "El Himno al placer"- que en un comienzo (por la similar formación humanista de ambos autores) estuvimos tentados de atribuir a Pedro Paz Soldán y Unánue. - ¿Qué relación pudo haber entre ambos, ya que Flores Galindo, según lo dice, vivió mucho tiempo en Cañete, cerca de Arona, y tal vez de González Prada que en esa época estaba recluído en la cercana Mala, y siendo así que los tres se empeñaron en traducir del alemán en sus respectivos retiros? Estos datos surgen de una versión paralela aparecida en el citado periódico (8).

(7) v. "E1 Chispazo", No 12, Lima, tnero 9 de 1892.

(8) v. "Paralelo" en "El Correo del Perú", No XXXVI, año VI, Lima setiembre de 1876 , versión paralela fechada en Cañete, julio de 1876 . 
El extraordinario fervor sur-peruano por Heine y otros románticos germanos.

Mientras en Lima son figuras aisladas las que cultivan el arte de traducir a los alemanes - como González Prada, Ricardo Palma, Juan de Arona, Federico Flores Galindo y José Mendiguren- en el sur del Perú se advierte una corriente más homogénea y coordinada en ese culto literario. Aparte del origen arequipeño de Pedro Paz Soldán y Unánue (Juan de Arona), hay otras figuras de la misma región que demuestran una inusitada inclinación por la lírica germana. No vamos a referirnos de nuevo a los traslados de Adriana Buendía y de Samuel Velarde, en cuyo libro Propio y ajeno (9) se consignan varias versiones de Heine, de las cuales alguna muestra se ha reproducido en la citada obra sobre Autores Germanos en el Perí. Pero cabe agregar el dato de las versiones que ahora se reproducen en el Florilegio, de Manuel Rafael Valdivia y Diego Masías y Calle, poetas prestigiosos de la generación romántica, que figuran en la antología titulada Lira arequipeña (10) y que tradujeron con fortuna a Heine y a otros románticos alemanes de comlenzos del siglo XIX. Modesto Molina, nacido en Tacna, podría agregarse a esta pléyadde de líricos sur-peruanos que encuentran tal vez una identificación más intensa con los alemanes por lo mismo que en Heine o en Koerner podía conjugarse el delicado eco romántico regional, con nota de afirmación terrígena y contenida emoción delicada, que ya fue consustancial con el alma sureña desdelos albores del siglo en la lírica de Mariano Melgar, precursor del romanticismo peruano antes de que arribaran los mensajes de escuela venidos del Viejo Mundo a mitad del siglo.

Poetas alemanes del siglo $X X$.

Nos es grato revelar a un felicísimo traductor de Rilke, inédito e ignorado hasta hoy, que oculta en su modestia y en su forzado alejamiento de los campos de la cultura, dones de exquisitez espiritual poco co-

(9) Samuel Velakdr, Propio y Ajeno, Arequipa, Tip. Cáceres, I\$99. La segunda parte de la obra esta dedicada a recoger las traducciones de Velarde de su poeta predilecto que fue Heine, y además de otros románticos como Poe, Hugo, Lamartine, Millevoye, Musset y otros poetas más modernos como Richepin y Verlaine.

(ı) Lira arequipeña, colección de poesías, Arequipa, Imp. de Manuel Pío Cháves, 1889. 
munes. Carlos Augusto Pásara, jurista congénito, traduce hoy a Rilke con los resultados que pueden apreciarse en las versiones que ofrece. mos en el Nuevo Florilegio. De "El ángel de la guarda" de Rainer María Rilke publicamos, por el interés específico de las variantes principalmente, sus dos versiones, una de ensayo y otra de logrado plan interpietativo.

No podemos prescindir tampoco de reproducir dos versiones de poetas más recientes, como Hans Carossa y Oskar Loerke, elaboradas en los últimos años, lo primera, por Emilio Adolfo Westphalen conjuntamente con Enrique Soløri Swayne. De Westphalen y Solari hemos publicado antes alguna versión de Goethe, y a todas ellas abonan la formación humanista y la sensibilidad literaria de sus autores, ya manifestada en sus respectivas y muy estimables obras literarias. La versión de Loerke se debe a la pluma de Víctor Li Carrillo, cuya formación filosófica en tierras germanas lo ha vinculado a los grandes problemas de la cultura y al conocimiento de la literatura alemana más significativa.

No hemos podido sustraernos al impulso de revelar estos nuevos datos que completan una investigación anterior, pues bien dicen que el hombre es hijo de sus obras y éstas ejercen una suerte de imperio sobre nuestras sucesivas actividades. Creíamos haber cerrado un capítulo de nuestros trabajos pero nos damos cuenta que es muy difícil clausurar un nuevo campo abierto al interés cultural. Por más que hoy nos ocupan los poetas de lad lengua francesare italiana, y su influjo en el Perú, no podríamos romper el ligamen con los poetas de habla alemana, tan vinculados a nuestro gusto y formación. Nos alientan múltiples circunstancias en estos trabajos de "literatura comparada", -sector sin duda un tanto descuidado por nuestros estudiosos, laguna que vamos drenando- y sobre todo sentimos vivo reconocimiento hacia la crítica com. prensiva, generosa y sensitiva que ha vislumbrado, aparte de nuestra persona, que los datos revelados por estos estudios, son la expresión del alto nivel espiritual de una sociedad culta. 